\title{
Hyperacute Infarct on Intraoperative Diffusion Imaging of Pediatric Brain Tumor Surgery
}

\author{
Christine Saint-Martin (1D, Sergio Apuzzo, Ayat Salman, Jean-Pierre Farmer
}

\begin{abstract}
Background: Brain neoplasms are the second-most prevalent cancer of childhood for which surgical resection remains the main treatment. Intraoperative MRI is a useful tool to optimize brain tumor resection. It is, however, not known whether intraoperative MRI can detect complications such as hyperacute ischemic infarcts. Methods: A retrospective analysis of pre- and intraoperative MRIs including DWI sequence and correlation with early and 3-month postoperative MRIs was conducted to evaluate the incidence of hyperacute arterial infarct during pediatric brain tumor resection. Patient demographics, pathological type, tumor location, resection type as well as preoperative tumoral vessel encasement, evolution of the area of restricted diffusion were collected and analyzed comparatively between the group with acute infarct and the control group. Extent of the hyperacute infarct was compared to both early postsurgical and 3-month follow-up MRIs. Results: Of the 115 cases, 13 (11\%) developed a hyperacute arterial ischemic infarct during brain tumor resection. Tumoral encasement of vessels was more frequent in the infarct group (69\%) compared to $25.5 \%$ in the control group. Four cases showed additional vessel irregularities on intraoperative MRI. On early follow-up, the infarcted brain area had further progressed in six cases and was stable in seven cases. No further progression was noted after the first week post-surgery. Conclusions: Hyperacute infarcts are not rare events to complicate pediatric brain tumor resection. Tumoral encasement of the circle of Willis vessels appears to be the main risk factor. Intraoperative DWI underestimates the final extent of infarcted tissue compared to early postsurgical MRI.
\end{abstract}

RÉSUMÉ: Présence d'infarctus ischémiques hyper-aigus révélés par des IRM peropératoires de diffusion dans le cas de chirurgies visant à traiter le cancer du cerveau chez l'enfant. Contexte : Chez l'enfant, les néoplasmes du cerveau viennent au second rang des cancers pour lesquels la résection chirurgicale demeure le principal traitement. L'IRM peropératoire est un outil efficace pour maximiser la résection d'une tumeur cérébrale. On ignore toutefois de quelle façon cet outil peut permettre de détecter des complications telles que les infarctus ischémiques hyper-aigus. Méthodes : Nous avons tout d'abord effectué une analyse rétrospective des IRM préopératoires et peropératoires, ce qui inclut des IRM de diffusion. Nous avons aussi cherché à établir des corrélations avec des IRM post-opératoires, certaines effectuées tout juste après une résection et d'autres après 3 mois, afin d'évaluer l'incidence d'infarctus ischémiques hyper-aigus survenant en cours de résection. Des données portant sur les caractéristiques des patients, sur la pathologie tumorale, sur l'emplacement des tumeurs, sur le type de résection ainsi que sur l'envahissement vasculaire tumoral préopératoire et sur l'évolution de la région de diffusion restreinte ont été collectées. Nous avons ensuite effectué une analyse comparative entre notre groupe de patients et un groupe de témoins. L'ampleur des infarctus ischémiques hyper-aigus a été comparée au moyen d'IRM réalisées tout juste après une résection et d'IRM de suivi après trois mois. Résultats : Sur un total de 115 cas, 13 (11\%) ont donné à voir un infarctus ischémique hyper-aigu au cours d'une résection. L'envahissement vasculaire tumoral était plus fréquent dans le groupe de jeunes patients ayant donné à voir un infarctus (69\%) comparativement à 25,5\% dans le groupe des témoins. Quatre cas ont aussi montré, lors d'IRM peropératoires, des irrégularités additionnelles en ce qui a trait aux vaisseaux sanguins. Lors de suivis effectués rapidement après une résection, les régions du cerveau affectées par un infarctus avaient continué à croitre davantage chez 6 cas et étaient demeurées stables chez 7 autres cas. Aucune autre progression n'a été notée à la suite d'une IRM menée une semaine plus tard. Conclusions : Les infarctus ischémiques hyper-aigus ne sont pas des événements inhabituels. Comme on le sait, ils peuvent entraîner des complications au moment d'effectuer la résection d'une tumeur cérébrale chez l'enfant. L'envahissement vasculaire tumoral du polygone de Willis semble être ici le principal facteur de risque. Les IRM de diffusion peropératoires ont tendance à sous-estimer l'étendue finale des tissus affectés par un infarctus ischémique comparativement aux IRM effectuées tout juste après une résection.

Keywords: Intraoperative Magnetic Resonance Imaging (ioMRI), Intraoperative Diffusion-Weighted Imaging (ioDWI), Hyperacute arterial infarct

doi:10.1017/cjn.2019.226

Can J Neurol Sci. 2019; 46: 550-558

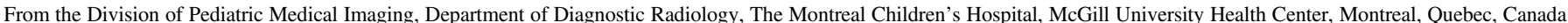

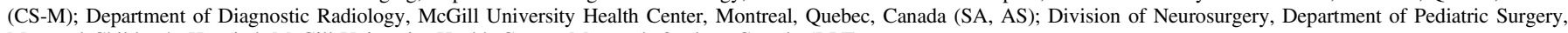
Montreal Children's Hospital, McGill University Health Center, Montreal, Quebec, Canada (J-PF)

Received October 29, 2018. Final Revisions Submitted April 30, 2019. Date of Acceptance May 30, 2019.

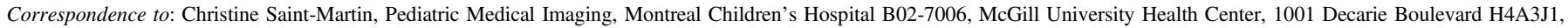
Montreal, Quebec, Canada. Email: christine.saint-martin@mcgill.ca 


\section{INTRODUCTION}

Though pediatric brain neoplasms are relatively uncommon, they are the second-most prevalent type of pediatric cancers. Approximately 4000 children are affected by a brain neoplasm per year in the USA. ${ }^{1}$ In the past century, advancements in radiology, neurosurgery, chemotherapy, radiotherapy along with recent technologies such as genetic profiling and targeted therapies have resulted in current 5-year survival rates of $73 \%$ for all pediatric brain tumors combined. Despite these advancements, surgery remains an important part of the successful management of pediatric CNS tumors. ${ }^{2}$

\section{Intraoperative Magnetic Resonance Imaging (IoMRI)}

Intraoperative MRI involves the use of an MRI during surgery by either bringing the MRI unit into the operating room (magnet to patient approach) or bringing the patient to an MRI suite adjacent to the operating room (patient to magnet approach), both using imaging on a patient immobilized in the surgical position within a specific intraoperative coil. Maximal resection of malignant pediatric brain neoplasms remains a key prognostic factor and offers the maximal chance for long-term survival. ${ }^{3-6}$ Consequently, the most frequent use of intraoperative MRI is for the removal of brain neoplasms to obtain maximal brain neoplasm removal while minimizing iatrogenic neurological damage. ${ }^{7-15}$

There is little use of diffusion tensor and diffusion-weighted imaging during intraoperative conditions of imaging. Most studies report the use of DWI and ADC sequences in preoperative assessment of brain space occupying lesions. Marupudi et al have shown that the ideal surgical strategy for resection of pediatric posterior fossa tumors, specifically medulloblastomas, is to begin resection from regions where the tumor contour is well defined, non-infiltrative, and proceed to areas where the tumor is infiltrating or invading the brainstem, based on diffusion sequence. They argued that preoperative ADC map best anticipates and helps delineate infiltrative planes between normal and neoplastic tissues and confirmed by comparing the ADC map predicted infiltrative planes with those observed intraoperatively. ${ }^{16}$

Some studies have shown that intraoperative diffusion tensor imaging can serve as an aid in assessing how white matter tracts shift in position during brain tumor resection. Consequently, intraoperative diffusion tensor imaging can help to improve neuronavigation during neurosurgery. This can maximize the extent of resection of brain tumor with maximal preservation of neurological function by sparing the eloquent areas. ${ }^{17}$

In 2013, Li and collaborators have shown that intraoperative diffusion tensor imaging can be used to evaluate corticospinal tracts throughout the course of insular tumor resections to minimize corticospinal tract injury. Intraoperative diffusion tensor imaging can be used to prevent postoperative motor function deficits and as prognostic indicator of motor function outcome following resection of insular tumors. ${ }^{18}$

\section{Objectives}

The main objective of the paper is to determine the frequency of hyperacute arterial infarcts diagnosed with intraoperative diffusion-weighted imaging during pediatric brain tumor resection at a single academic tertiary pediatric care center with high volume of brain tumor management.
We hypothesize the rate of hyperacute infarct occurring during surgery is underestimated as it could be difficult to clinically recognize in the early postoperative period due to the variability of both the patient's recovery and potential neurological symptoms due to the infarct. We hypothesize that intraoperative diffusion-weighted imaging may help to identify hyperacute ischemic arterial infarcts that will potentially affect the immediate postoperative course, the therapeutic strategy, and the short-term clinical outcome.

\section{Materials And Methods}

A retrospective analysis of preoperative and intraoperative MRIs including DWI sequence and correlation with early and 3-month postoperative MRIs was conducted to evaluate the incidence of hyperacute arterial infarct during pediatric brain tumor resection.

The inclusion criteria were pediatric patients aged from 0 to 18 years old, for which intraoperative MRI obtained during brain tumor resection, included diffusion-weighted images and apparent diffusion coefficient mapping. All the intraoperative MRI studies performed before 2013 were excluded due to the absence of diffusion-weighted sequence. Patients with no available follow-up MRI were excluded.

Selected post-contrast T1-weighted sequences of the examinations obtained at diagnostic imaging were reviewed to assess the preoperative vessel encasement.

The IoMRI protocol included 3D T1 pre- and 3D T1 postcontrast-weighted images obtained in the sagittal plane covering the full brain (FOV $250 \times 250 \mathrm{~mm}$, slice thickness $1.2 \mathrm{~mm}$, no gap, TR $5 \mathrm{~ms}$, TE $2.3 \mathrm{~ms}$, flip angle 12 degrees), 3D T2-weighted sequence in the sagittal plane (FOV $250 \times 250 \mathrm{~mm}$, slice thickness $1 \mathrm{~mm}$, no gap, TR $2500 \mathrm{~ms}$, TE $380 \mathrm{~ms}$, flip angle 90 degrees), a 30-direction spin-echo echoplanar DTI sequence (transverse plane, FOV $250 \mathrm{x}$ $250 \mathrm{~mm}$, slice thickness $2 \mathrm{~mm}$, no gap, TR 8000-9000 ms, TE $60 \mathrm{~ms}$, partial Fourier in phase direction) from which the isotropic image $(b$ value $=800)$ and the ADC maps were provided for the visual analysis of signal changes. Then, the ADC value of the largest surface area of restricted diffusion as well as the ADC value of a mirrored surface area on the contralateral side of the brain were compared using the diffusion analysis software on Intelespace Philips server.

IoMR images are analyzed at the time of acquisition by one of the senior pediatric neuroradiologists and the operating neurosurgeon in consensus. Image analysis includes assessment of degree of tumor resection and diagnosis of acute complication including hyperacute ischemic infarcts. This approach provides an opportunity to institute early anti-vasospasm medication in the operative room or in the intensive care unit.

Hyperacute infarct is suspected when an area of restricted diffusion that could correspond to a vascular arterial territory is seen distant or remote from the usually seen and expected restricted diffusion along the immediate contours of the surgical bed.

When early postoperative MRI is performed, it occurs outside of the surgical conditions during the first 10 days after surgery, with a non-sedated patient coming from the floor. Since it is usually requested to assess the size of the ventricular system, it includes fast SE T2-weighted sequences done in both the coronal and axial planes; however, other sequences including diffusionweighted imaging are performed on a case-based decision. 
Delayed imaging is routinely obtained 3 months after surgery with multiple sequences including diffusion, T2, FLAIR (fluidattenuated inversion recovery), pre- and post-contrast 3D T1-weighted imaging.

\section{Data Collection}

Patient demographics, tumor location, pathological type, resection type as well as preoperative tumoral vessel encasement, intraoperative vessel irregularity or asymmetry were collected and analyzed comparatively between the group with acute infarct (group B) and the control group without (group A).

The relationship between the brain tumor and the surrounding major cerebral arteries was investigated on post-contrast T1-weighted imaging and correlated to MRA when available, with specific attention to both the arterial encasement and the contour irregularities. Asymmetry or irregular vessel caliber is presumed to correspond to both vasospastic arteries and chronically stretched/ compressed arteries secondary to the mass effect of the brain tumor. The vascular territory of the identified vessel was correlated with the location of the hyperacute intraoperative infarct.

Extent of the hyperacute infarct was compared to both early postsurgical and 3-month follow-up MRIs.

\section{RESULTS}

\section{General Findings (Refer to Table 1)}

Of the 115 surgeries, 13 cases (about 11\%) were complicated with a hyperacute arterial infarct. There was no difference in the male:female ratio between the control group A of 102 surgeries $(1,63)$ and the group B of 13 acute infarcts $(1,33)$. Mean age of the patients with a hyperacute infarct (6.5 years) was 15 months younger than in the control group ( 7,8 years).

While two-thirds of the tumors were supratentorial in location in the control group, $62.5 \%$ were in the posterior fossa in the group B of infarcts.

Pathology type of the resected mass lesion was grossly similar between the two groups, with a majority of low-grade WHO grade 1 and 2 (53\% in group A, $61 \%$ group B), compared to $35 \%$ of grade 3 and 4 in group A and $38 \%$ in group B. Of these 13 cases, the tumor pathological type included medulloblastoma $(n=3)$, pilocytic astrocytoma $(n=3)$, and one of each of the following: glioblastoma, anaplastic ependymoma, craniopharyngioma, epidermoid cyst, anaplastic ganglioglioma, desmoplastic infantile ganglioglioma, and hypothalamic hamartoma. (Figures 1-4).

The resection type differed between the two groups. In the control group, gross total resection was achieved in 53\% of the patients including four cases of further extent after IoMRI diagnosed subtotal resection. Subtotal resection, including two cases of further extent, was achieved in about $30.4 \%$. Biopsy and planned partial resection represented less than $20 \%$ of the surgeries. In the group B with infarcts, about the same number of subtotal $(n=6)$ and gross total $(n=5)$ resection were achieved while two patients underwent either a biopsy or a planned partial resection.

\section{Vascular Evaluation (Refer to Table 2)}

Tumoral encasement of vessels is noted in 9 of the 13 group B cases $(69 \%)$ compared to 26 of the 102 group A cases $(25.5 \%)$ with the involvement of the anterior circulation (4 cases) and of the posterior circulation (5 cases) (Figure 3).

\section{Table 1: Summary of the results}

\begin{tabular}{|c|c|c|}
\hline $\begin{array}{l}\text { TOTAL } 115 \text { surgeries } \\
101 \text { patients }\end{array}$ & $\begin{array}{l}\text { GROUP A No } \\
\text { complication } \\
88 \text { patients }\end{array}$ & $\begin{array}{c}\text { GROUP B Acute infarct } \\
13 \text { patients }\end{array}$ \\
\hline Male/female ratio & $55 \mathrm{M} / 33 \mathrm{~F}=1.63$ & $7 \mathrm{M} / 6 \mathrm{~F}=1.33$ \\
\hline Mean age at surgery & 7.8 years & 6.5 years \\
\hline \multicolumn{3}{|c|}{ PATHOLOGY } \\
\hline WHO grade 1 & 50 & 6 \\
\hline Who grade 2 & 4 & 2 \\
\hline Who grade 3 & 8 & 1 \\
\hline Who grade 4 & 28 & 4 \\
\hline Not classified & 6 & 0 \\
\hline Vascular malformation & 6 & 0 \\
\hline \multicolumn{3}{|c|}{ LOCATION } \\
\hline Supratentorial & 61 & 5 \\
\hline Infratentorial & 41 & 8 \\
\hline \multicolumn{3}{|c|}{ TYPE OF SURGERY } \\
\hline GT & 50 & 4 \\
\hline ST converted in GT & 4 & 1 \\
\hline ST extended & 2 & 0 \\
\hline ST & 29 & 6 \\
\hline PP & 12 & 1 \\
\hline biopsy & 5 & 1 \\
\hline \multicolumn{3}{|c|}{ VESSEL ANALYSIS } \\
\hline Preop MRA & $11 / 102$ & $1 / 13$ \\
\hline Preop 3D T1 gado & $96 / 102$ & $13 / 13$ \\
\hline $\begin{array}{l}\text { Vascular encasement on } \\
\text { preop }\end{array}$ & $26 / 102$ & $8 / 13$ \\
\hline $\begin{array}{l}\text { Vascular irregularity on } \\
\text { intraop 3D gado }\end{array}$ & $6 / 26$ & $4 / 8$ \\
\hline \multicolumn{3}{|c|}{ FOLLOW-UP } \\
\hline $\begin{array}{l}\text { First postsurgical MRI } \\
\text { delay }\end{array}$ & 48 days & 6 days \\
\hline Fast $\mathrm{T} 2$ vs $\mathrm{T} 2$ and $\mathrm{DWI}$ & 27 vs 75 & $5 / 9$ \\
\hline Early follow-up evolution & No infarct & 7 stable, 6 worse \\
\hline Delayed postsurgical MRI & 98 days & 92 days \\
\hline Late evolution & No new infarct & Stable $13 / 13$ \\
\hline
\end{tabular}

$\mathrm{GT}=$ gross total; $\mathrm{ST}=$ subtotal; $\mathrm{PP}=$ planned partial.

Mass effect on the adjacent vessels was noted in 10 out of 13 cases.

Additional vessel contour irregularity was diagnosed in four cases on intraoperative post-contrast $\mathrm{T} 1$-weighted imaging, mostly but not only involving the encased vessels. One patient who underwent a brainstem mass biopsy developed vasospasm of the basilar artery, and one patient with a large craniophayngioma encasing the supraclinoid carotid artery developed vasospasm of the ipsilateral anterior cerebral artery (Figure 1).

Three-fourth of the group B supratentorial tumors combined the three factors (encasement, mass effect, and vessel irregularities), 
Table 2: Specific characteristics of the group B patients

\begin{tabular}{|c|c|c|c|c|c|}
\hline \multicolumn{2}{|c|}{ Tumor Location and pathology type } & \multirow{3}{*}{$\begin{array}{c}\text { Surgery type } \\
\text { ST }\end{array}$} & \multicolumn{2}{|c|}{ Vascular involvement } & \multirow{3}{*}{$\begin{array}{c}\begin{array}{c}\text { Territory of the hyperacute } \\
\text { infarct }\end{array} \\
\\
\begin{array}{c}\text { Right anterior choroidal } \\
\text { artery, Right MCA and } \\
\text { Right ACA territories }\end{array} \\
\end{array}$} \\
\hline & & & \multirow{2}{*}{\begin{tabular}{|c|} 
Encasement \\
$\begin{array}{c}\text { Right-sided anterior circle of } \\
\text { Willis }\end{array}$
\end{tabular}} & \multirow{2}{*}{$\frac{\text { Mass effect }}{\text { Anterior circle of Willis }}$} & \\
\hline Supratentorial & $\begin{array}{l}\text { Sellar/suprasellar } \\
\text { craniopharyngioma WHO } \\
\text { grade } 1\end{array}$ & & & & \\
\hline & $\begin{array}{l}\text { Sellar/suprasellar epidemoid } \\
\text { cyst }\end{array}$ & GT & $\begin{array}{c}\text { Left-sided anterior circle of } \\
\text { Willis }\end{array}$ & $\begin{array}{l}\text { Left ICA SC, left A1, } \\
\text { left M1 }\end{array}$ & $\begin{array}{c}\text { Left anterior lentriculo-striate } \\
\text { arteries }\end{array}$ \\
\hline & Suprasellar hamartoma & GT & $(-)$ & $(-)$ & Anterior bithalamic arteries \\
\hline & $\begin{array}{l}\text { Right temporo-parietal } \\
\text { anaplastic ependymoma }\end{array}$ & GT & $\begin{array}{c}\text { M3 segment of the right } \\
\text { MCA }\end{array}$ & $(-)$ & $\begin{array}{l}\text { Right M3 branches: } \\
\text { rolandic and anterior } \\
\text { parietal arteries }\end{array}$ \\
\hline & $\begin{array}{l}\text { Left hemispheric } \\
\text { desmoplastic infantile } \\
\text { ganglioglioma }\end{array}$ & ST & $\begin{array}{l}\text { Left MCA (M1 and M2) } \\
\text { and left ICA SC }\end{array}$ & Left ICA SC & $\begin{array}{l}\text { Left anterior MCA and } \\
\text { hippocampal branches of } \\
\text { left anterior choroidal } \\
\text { artery }\end{array}$ \\
\hline \multirow[t]{8}{*}{ Infratentorial } & Medulloblastoma & GT & Right PICA & Bilateral PICA & Right PICA medial territory \\
\hline & Medulloblastoma & ST & $(-)$ & Bilateral PICA & Right PICA medial territory \\
\hline & $\begin{array}{l}\text { Cervical-medullary } \\
\text { pilocytic astrocytoma }\end{array}$ & ST & Right PICA & Right PICA & Right PICA medial territory \\
\hline & Medulloblastoma & GT & Right and Left PICA & Bilateral PICA & $\begin{array}{l}\text { Right and left PICA medial } \\
\text { territory }\end{array}$ \\
\hline & $\begin{array}{l}\text { Right middle cerebellar } \\
\text { peduncle pilocytic } \\
\text { astrocytoma }\end{array}$ & ST & Right SCA & Right SCA and AICA & Right SCA territory \\
\hline & $\begin{array}{l}\text { Midbrain pilocytic } \\
\text { astrocytoma }\end{array}$ & ST & $(-)$ & $(-)$ & Splenial artery \\
\hline & Ependymoma WHO grade 3 & ST & Right PICA and AICA & Right PICA and AICA & Right PICA and AICA \\
\hline & Glioblastoma brainstem & Biopsy & $(-)$ & Left PICA & $\begin{array}{c}\text { Junctional PICA-SCA } \\
\text { bilateral }\end{array}$ \\
\hline
\end{tabular}

$\mathrm{MCA}=$ middle cerebral artery; $\mathrm{ACA}=$ anterior cerebral artery; PICA = posterior inferior cerebellar artery; SCA = superior cerebellar artery; ICA = internal carotid artery; $\mathrm{SC}=$ supraclinoid segment.

while the same proportion of posterior fossa tumors combined only two factors (encasement and mass effect).

There was a perfect correlation between the identified abnormal arteries and the vascular territory of the hyperacute infarct. In the two cases of sellar and suprasellar large mass lesions encasing the anterior circle of Willis, (Figure 1) infarcts were diagnosed in the right ACA, MCA, and AchA in one patient and in the left lenticulostriate territory in the other one. One patient had a large peripheral temporal-parietal mass lesion encasing the M3 branches of the right MCA and she developed an ischemic infarct in the corresponding right rolandic, anterior, and postcentral parietal regions (Figure 2). One young male patient with a large hemispheric mass encasing the left ICA supraclinoid segment and the left MCA M1 and M2 segments developed multifocal infarcts in the left superficial MCA as well as in the left anterior choroidal artery territories (Figure 3). Finally, five patients with a cerebellar mass lesion developed acute ischemic infarcts in part of the territory of the ipsilateral encased PICA with no surgical mention the vessel had been ligated during the surgery (Figure 4).

In the control group, 26 out of 102 patients $(25.5 \%)$ had a tumor encasing the vessels on preoperative imaging. Additional vascular contour irregularities were noted on the intraoperative $\mathrm{T} 1$ post-contrast sequence in six of those cases $(23 \%)$.

\section{ADC Values}

The ADC value of the area of restricted diffusion as well as the ADC value of the same surface area on the contralateral side were retrospectively measured using the diffusion analysis software on Intelespace Philips server. The average ADC value of the areas of suspected acute ischemic infarct was significantly lower $\left(0.64 \quad 10^{-3} \mathrm{~mm}^{2} / \mathrm{sec}\right)$ $(p<0.05)$ than the value of the contralateral area of normal appearing parenchyma $\left(0.8710^{-3} \mathrm{~mm}^{2} / \mathrm{sec}\right)$. Due to the small number of cases, a cut-off value could not be reliably established.

\section{Evolution of the Hyperacute Infarcts (Refer to Figure 5)}

Early postoperative MRI was performed in a shorter delay in the group of affected patients compared to the control group (12 days compared to 28 days). No false-positive intraoperative diffusion findings could be found.

Out of 13, 4 infarcts were, however, diagnosed retrospectively on the analysis of the early postoperative MRI and were confirmed to be present on the intraoperative diffusion sequence but either 


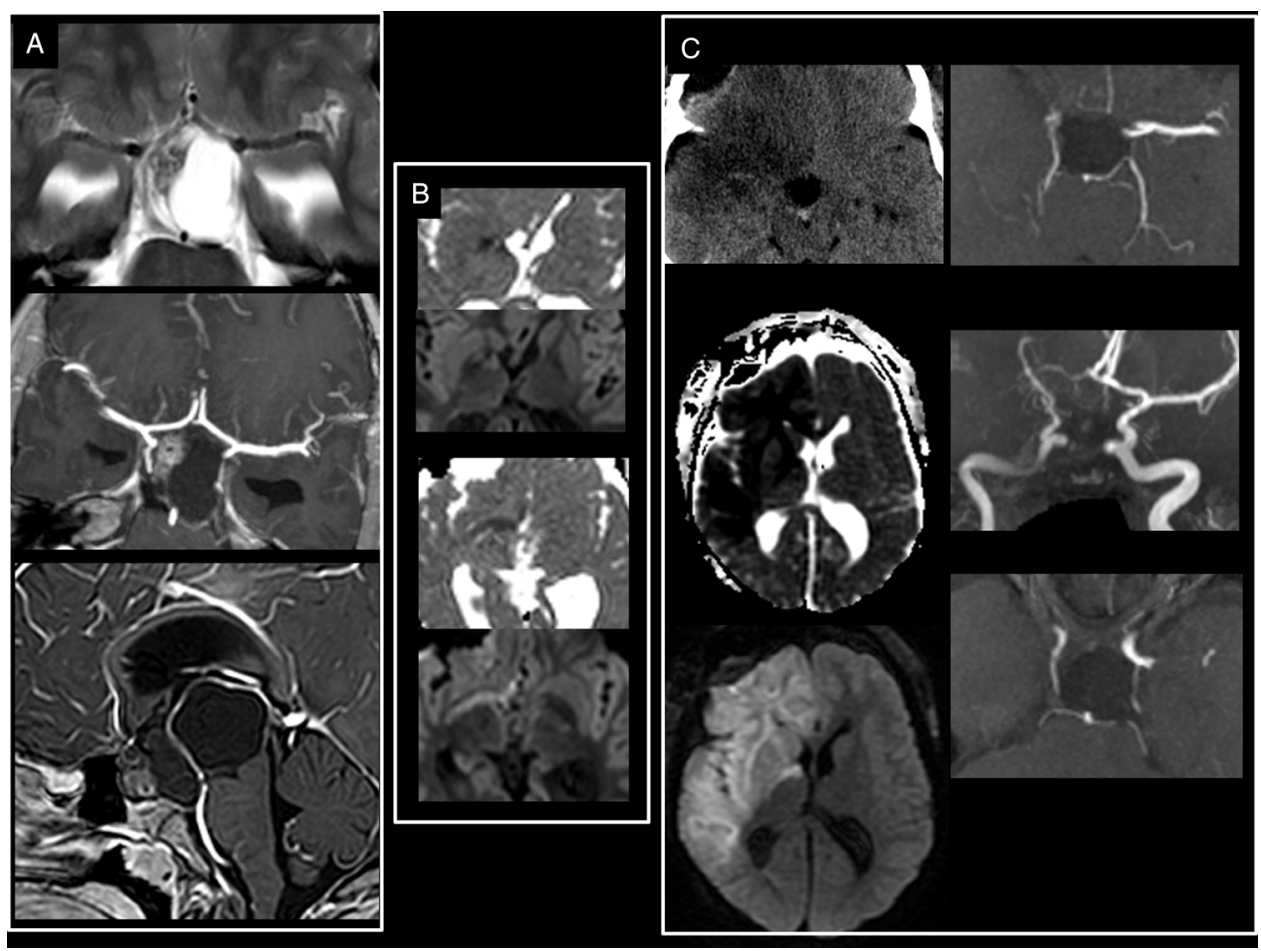

Figure 1: Large craniopharyngioma encasing the right circle of Willis. (A) Preoperative T2-weighted and T1-weighted post-gadolinium administration show a large craniopharyngioma encasing the right ACA, $M C A$ as well as the supraclinoid segment of the right ICA. (B) Intraoperative axial isotrace and ADC maps at the level of the basal ganglia show restricted diffusion from a hyperacute infarct of the posterior limb of the right internal capsule which is irrigated by branches from the right anterior choroidal artery. (C) Early postoperative unenhanced $C T$ and MRI ADC map and isotrace images show the significant progression of the ischemia encompassing both the right ACA and right MCA vascular territories. Postoperative $3 D$ TOF$M R A(C)$ done on day 11 postsurgery confirmed a persistent narrowing of the right ICA and the absence of flow in the right MCA, both vessels encased but not narrowed on initial diagnostic imaging.

very small in size (punctate area within the callosal splenium) or initially thought to be related to susceptibility artifacts.

Early evolution of the infarcts was assessed with MRI performed between day 2 and day 10 (median day 5) after surgery. Two main patterns of evolution of the hyperacute infarcts are identified with essentially stability $(n=7)$ and progression $(n=6)$. One of the patients with a stable infarct benefited from immediate postoperative measures to counter vasospasm. In five out of six cases where early progression in size of the hyperacute infarct was noted, it was still following the same vascular territory. Only one case of hyperacute infarct, associated with per-operative vasospastic activity obviously seen on both imaging and during the surgery, developed new infarcts in vascular territories irrigated by the vasospastic arteries, despite the administration of vasoplegic medications during the resection (Figure 1).

For all the 115 surgical cases, the follow-up MR imaging done with a mean delay of 3 months (98 days group A, 92 days group B) after the surgery confirmed no new event in both groups and no further progression of the infarct after the early immediate postoperative period.

\section{Discussion}

\section{Frequency of Hyperacute Infarcts}

We present the first report of acute ischemic arterial infarcts as a complication of resection of brain tumor in the pediatric population, diagnosed with the help of intraoperative MRI.
In our study, hyperacute infarcts are not rare events during pediatric brain tumor resections, since approximately $11 \%$ of pediatric brain resection cases were complicated by a hyperacute infarct (13 of 115 cases).

Currently, there are no published studies identifying the frequency of neurosurgeries complicated by a perioperative brain infarct in the pediatric population. There are, however, a few studies conducted in the adult population. A study from De la Garza-Ramos et al. suggests that the iatrogenic stroke incidence after elective cranial neurosurgery for malignant brain tumors ranges from $1 \%$ to $2 \%$ in the adult population. ${ }^{19}$ Khomand etal. have determined that the incidence of cerebrovascular accidents following brain tumor surgery in the adults was $2 \% .{ }^{20}$ Similar to the results of our study, Khomand et al. have identified that the frequency of postsurgical stroke following neurosurgery was neither affected by patient age or sex, nor by tumor type, location, or type of intervention used for tumor removal. ${ }^{20}$ In a study by Gempt et al. analyzing the incidence of infarctions following glioma resection, $31 \%$ of patients were found to have new postoperative ischemic lesions identified with early postoperative diffusion-weighted imaging. ${ }^{21}$ Similarly to our study, this group of authors has concluded that the proximity of the brain tumor to central cerebral arteries is the greatest risk factor for early postsurgical infarcts. $^{21}$

Regarding the physiopathology of these hyperacute ischemic arterial infarcts, several hypotheses are discussed although not supported by any animal experimental model. Since sacrifice or direct injury of the encased vessel was not mentioned in the 


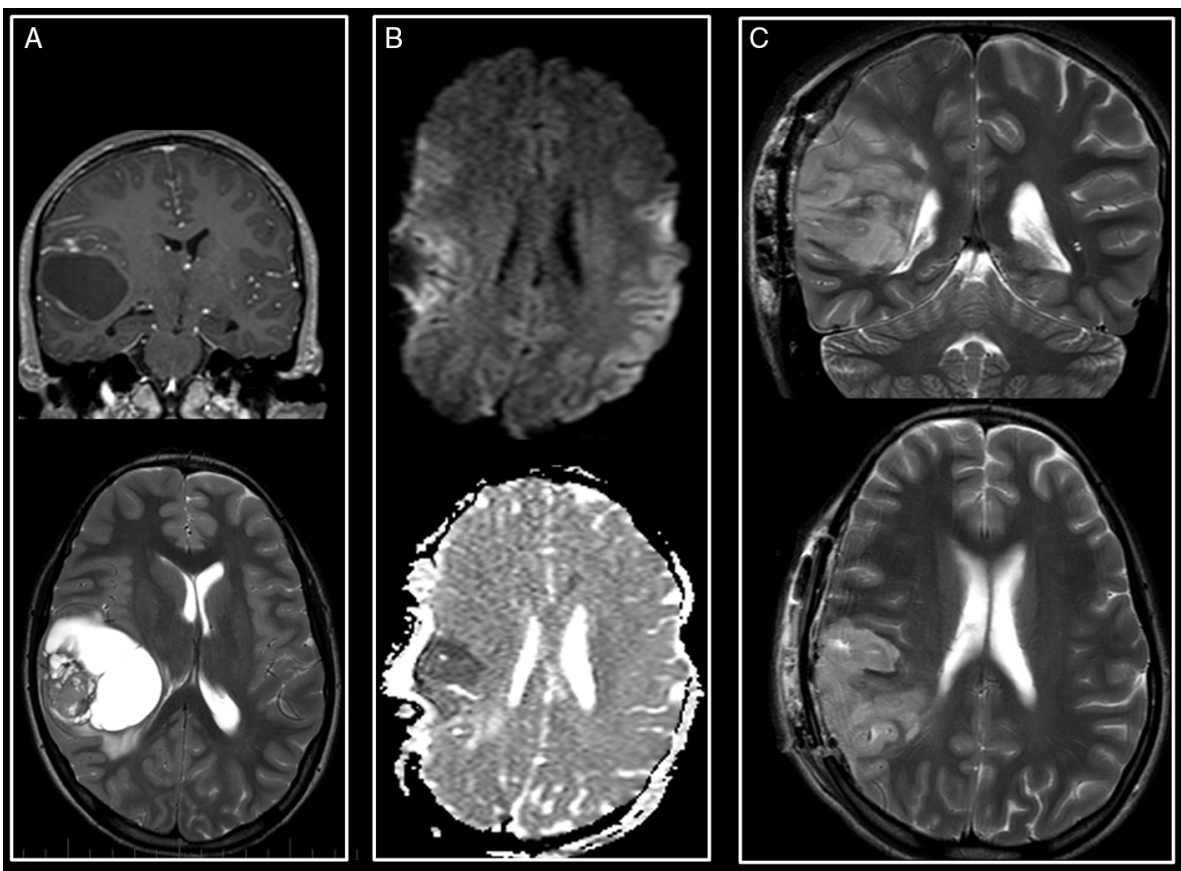

Figure 2: Supratentorial hyperacute infarct. (A)Preoperative T1-weighted with gadolinium coronal and T2-weighted images of an anaplastic ganglioglioma of the posterior right insula. (B) Intraoperative axial trace and $A D C$ maps reveal a hyperacute infarct in the territory of the superior M3 branch of the right MCA. (C) Early postoperative coronal and axial T2-weighted images show progression in size of the infarct with no hemorrhagic transformation.
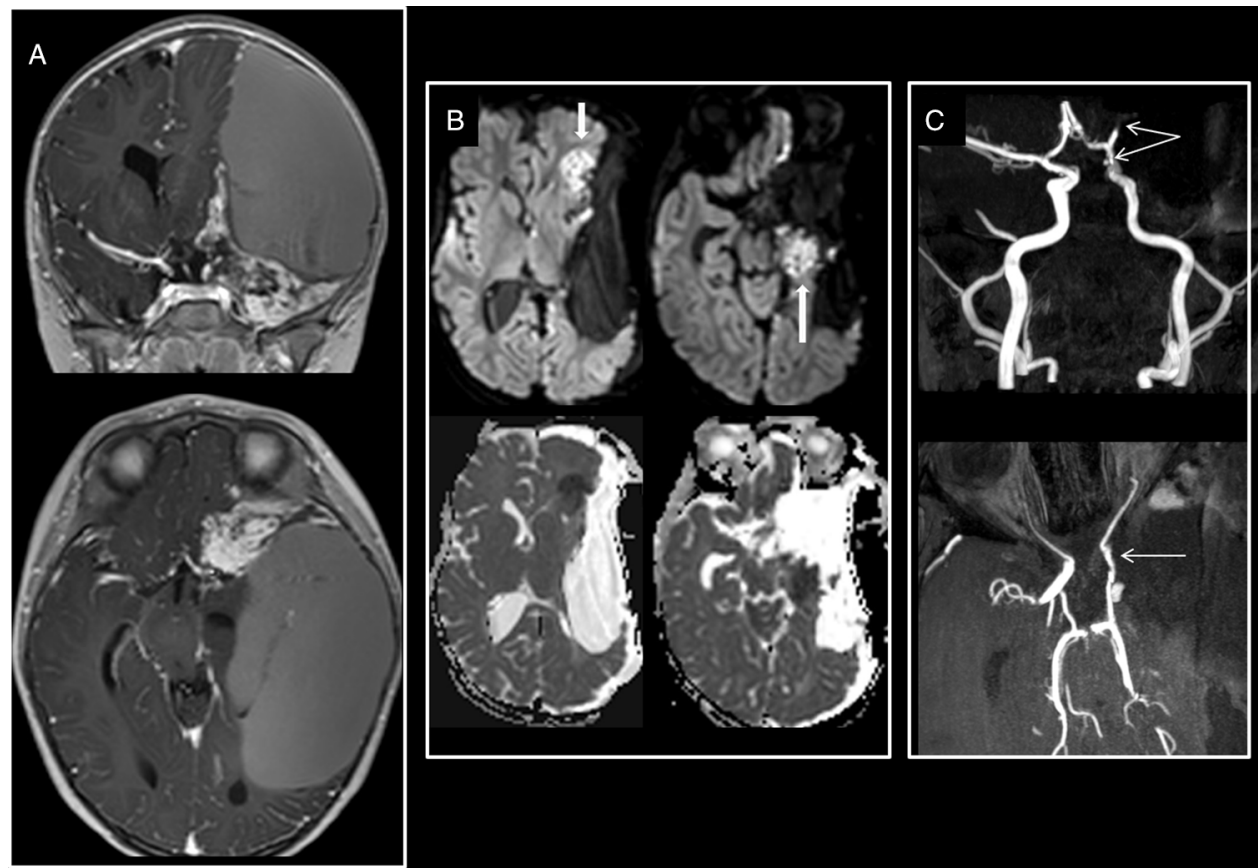

Figure 3: Supratentorial hyperacute infarct. Left insular desmoplastic infantile ganglioglioma encasing the left anterior circle of Willis on preoperative T1-weighted images with gadolinium (A). Intraoperative axial trace and $A D C$ map $(B)$ show hyperacute infarcts in the territories of the hippocampal branch of the left anterior choroidal and of the anterior branch of the left middle cerebral arteries. $(C)$ Postoperative MRA-TOF shows narrowing of the encased supraclinoid segment of the left ICA and the absence of visibility of the left MCA M2 and M3 segments 


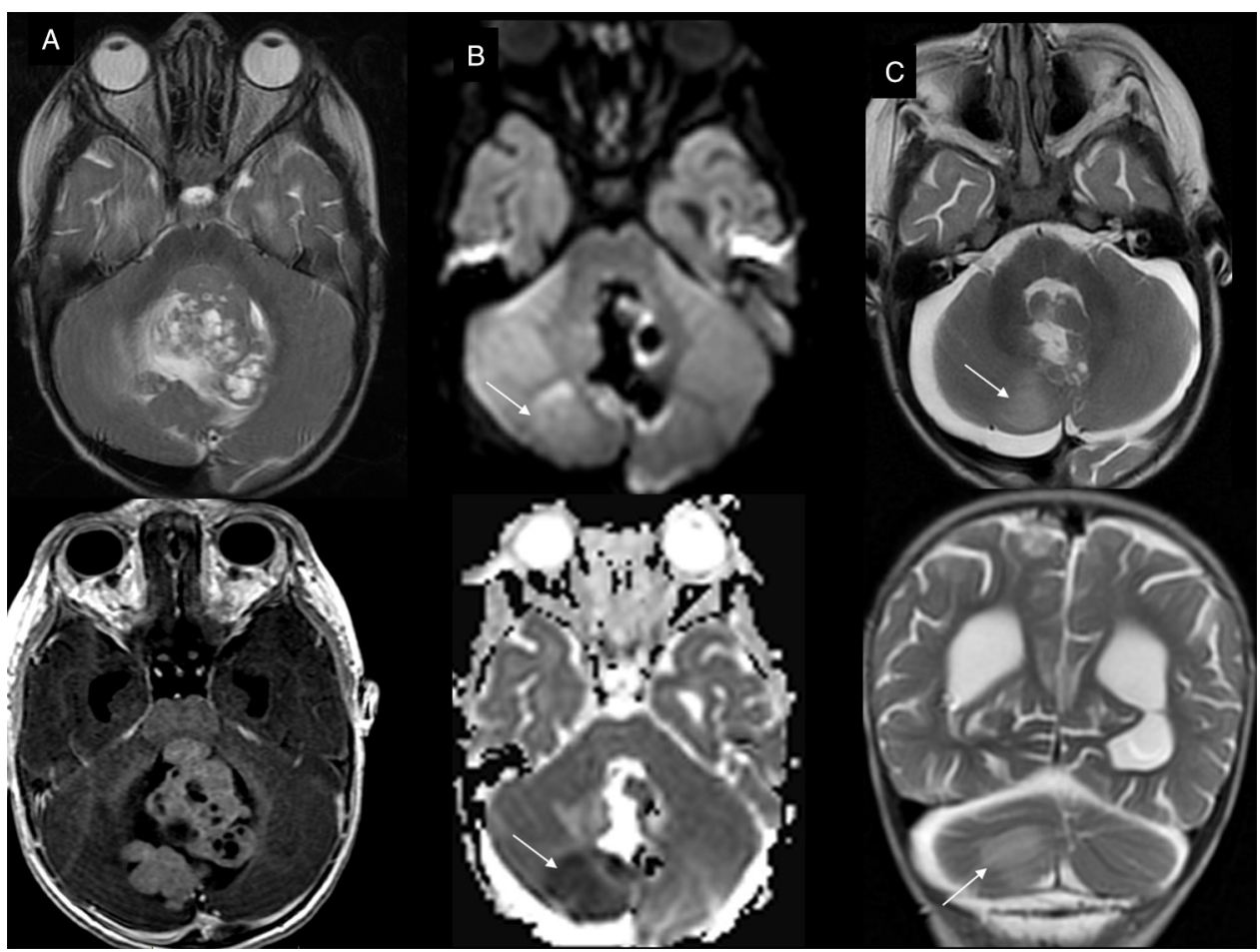

Figure 4: Posterior fossa hyperacute infarct. (A)Preoperative T2- and T1-weighted with gadolinium axial view of the large posterior fossa medulloblastoma. (B) Intraoperative trace and ADC maps show restricted diffusion in the territory of the medial branch of the right PICA, confirmed and stable in extent on early postoperative T2-weighted images $(C)$.
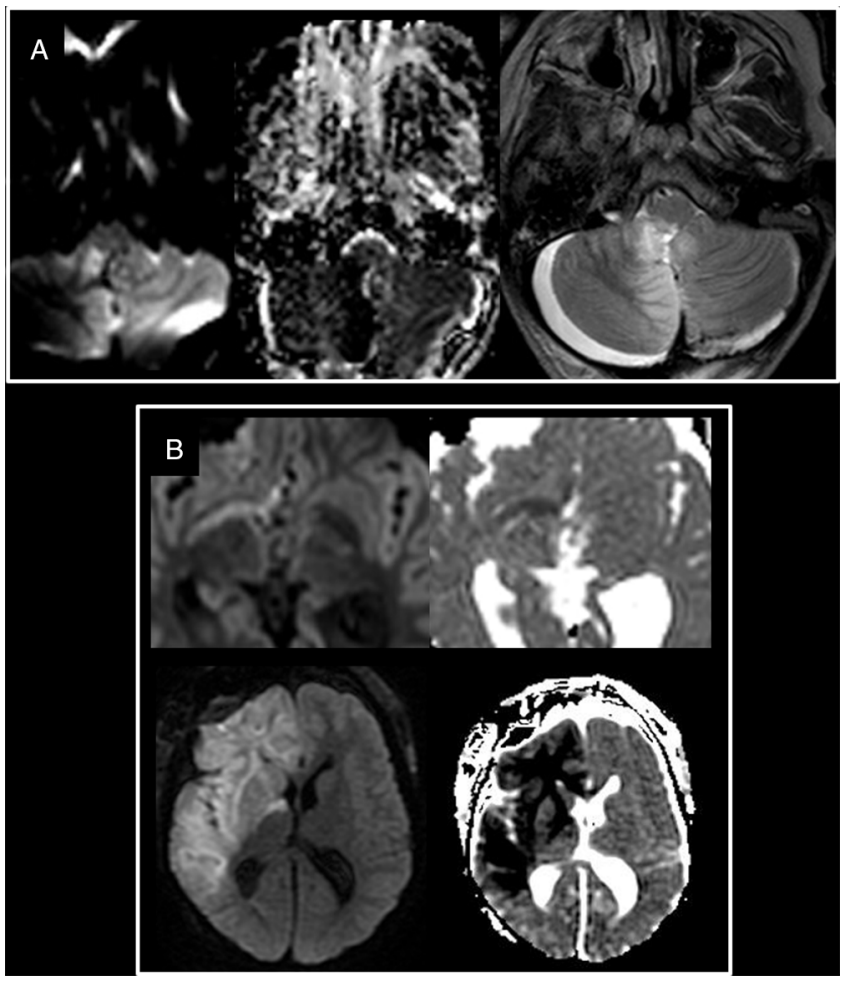

Figure 5: Patterns of hyperacute infarct evolution. (A) Stable evolution of the right PICA infarct between the IoMRI (left and middle) and the early follow-up (right). (B) Progression in extent with new territories involved between the intraoperative (top) and the early follow-up (bottom). 
surgical reports of our 13 cases, we could rather hypothesize a difficult surgical dissection of the tumor had led to artery irritation, subsequent intraoperative vasospasm, eventually to hypoperfusion and infarct formation. The early postoperative progression of the arterial infarct favors a progressive mechanism of ischemia induced by vasospasm rather than an acute obstructive phenomenon. This is where early knowledge of ischemic changes can lead to anti-vasospasm therapeutic interventions to limit the ischemic penumbra. Three of the presented patients benefited from such treatment.

We noted vessel encasement was present in $69 \%$ of the cases with infarct compared to $25.5 \%$ in the group without infarcts. In addition, irregularity of the encased vessels is more than twice more frequent (69\%) in the group of developing infarcts compared to the control group (23\%). The combination of vessel encasement, mass effect, and vessels irregularities appears dominant in the development of further ischemic complications, as it was found in three-fourth of the group B patients with three signs (supratentorial tumors) and two signs (infratentorial tumors) combined. This apparent correlation should prompt radiologists to systematically report these findings and to notify neurosurgeons of patients at a likely risk of developing hyperacute infarcts during surgery.

The preoperative and intraoperative $\mathrm{T} 1$ with gadolinium 3D sequence should be carefully analyzed and additional MR angiogram could be performed when encasement of vessels is suspected based on the pre-contrast sequences.

\section{Use of IoMRI to Diagnose HAI}

In our daily practice, IoMR images are analyzed at the time of acquisition, by one of the senior pediatric neuroradiologist and the operating neurosurgeon in consensus. Image analysis includes assessment of degree of tumor resection and diagnosis of acute complication including hyperacute ischemic infarcts. This approach provides an opportunity to institute early antivasospasm medication in the operative room or in the intensive care unit

Intraoperative DWI can, however, be difficult to interpret due to the anatomical distortion, due to potentially extensive susceptibility artifacts, mainly related to the open skull, to air present in the surgical bed as well as to artifacts related to the metallic pins used to immobilize the patient's head within the intraoperative coil. To minimize these artifacts, isotrace and ADC maps are obtained from a medium DTI sequence which is applying the gradients in 30 directions and is used to compensate the low signal:noise ratio of the regular EPI diffusion sequence in which the gradients are applied in only three directions.

Diffusion signal changes could be very subtle and focal in addition to distant from the surgical bed which lead to a high risk of missed diagnosis in the acute phase. There were no falsepositive cases; however, four infarcts were diagnosed retrospectively, after reading the early postoperative exam and reviewing the ioDWI, either due to the small size of the infarct or due to very subtle initial changes in signal intensity. In the case where the infarct was involving the splenium of the corpus callosum, the retrospective analysis of the intraoperative MRI revealed a much smaller and punctate area of restricted diffusion in the mid-aspect of the splenium of the corpus callosum. In the other three cases of non-evolving infarct, initial signal changes were discrete in intensity and measurements of differential ADC values confirmed positive restricted diffusion. Based on our experience, we recommend having a meticulous analysis of both the trace and the ADC maps.

Both the limitations of ioDWI and the underestimated final extent of infarcted tissue raise the indication of doing an early postoperative MRI to assess the progression of the infarct with a fast T2 imaging as it is easy and short to perform without the need of either sedation or contrast injection.

\section{Limitations}

Our study has limitations in the methodology, since only one radiologist was involved in reading all the intraoperative MRIs.

As a retrospective study, no systematic correlation with the clinical outcome could be properly carried out, and clinical data gathered did not document any specific neurological deficits related to the vascular territory of the infarcted brains. In addition, due to the specific or unique tumor or surgery specifications, there was no possible correlation among patients with similar tumors without and with perisurgical/hyperacute infarcts.

Finally, the absence of systematic MR angiogram done prior to the surgery limits the evaluation of the vascular properties of these tumors as these were mainly assessed on volumetric T1-weighted acquisition obtained with gadolinium injection.

\section{Conclusion}

In conclusion, this study suggests that hyperacute infarct is not a rare event to complicate pediatric brain tumor resections and it may be beneficial to identify those patients at risk prior to surgery. Neuroradiologists should seek for tumoral encasement of cerebral arteries, mass effect, and asymmetric vessel caliber from either vasospasm or chronic mass effect from the encasing tumor, based on the preoperative T1 with gadolinium 3D sequence. Intraoperative DWI carries a very high detection rate but appears to underestimate the final extent of infarcted tissue. Hence, early postoperative fast MRI is recommended, even more in cases with risks factors for perioperative/hyperacute infarct such as vascular encasement, mass effect, or vascular irregularities.

\section{Abbreviations}

$$
\begin{aligned}
& \text { DTI }=\text { Diffusion tensor imaging } \\
& \text { ADC }=\text { Apparent Diffusion Coefficient } \\
& \text { MRA }=\text { Magnetic Resonance Angiography } \\
& \text { OR }=\text { Operating Room } \\
& \text { ACA }=\text { Anterior Cerebral Artery } \\
& \text { MCA }=\text { Middle Cerebral Artery } \\
& \text { ICA }=\text { Internal Carotid Artery } \\
& \text { PCA }=\text { Posterior Cerebral Artery } \\
& \text { PCA }=\text { Posterior Inferior Cerebellar Artery } \\
& \text { SCA }=\text { Superior Cerebellar Artery }
\end{aligned}
$$

\section{STATEMENT of Authorship}

Dr. CS-M has designed the study, has reviewed all the material (MRIs), has supervised SA, during collection and analysis of the diseased subgroup, has revised and amended the first version of the article.

Dr. SA has collected and analyzed the date of the diseased subgroup, has compiled the literature and participated in the writing of the article. 
AS has reviewed the study design and the submission to the ethics board. Dr. J-PF has contributed to the data collection and analysis and reviewed the initial version. All the authors have reviewed and agreed with the final revised version of the article.

\section{Disclosures}

The authors have no conflicts of interest to declare.

\section{ACKNowledgments}

The authors would like to acknowledge Dr. J. Atkinson, Dr. R. Dudley, Dr. J Montes and Dr. N. Wilson for their contribution and continuous support to the project.

\section{REFERENCES}

1. Ostrom QT, Gittleman H, Farah P, et al. CBTRUS statistical report: primary brain and central nervous system tumors diagnosed in the United States in 2006-2010. Neuro Oncol. 2013;00(002):1-56.

2. Karajannis M, Allen JC, Newcomb EW. Treatment of pediatric brain tumors. J Cell Physiol. 2008;217(3):584-9.

3. Finlay JL, Wisoff JH. The impact of extent of resection in the management of malignant gliomas of childhood. Childs Nerv Syst. 1999;15(11-12):786-8.

4. Albright AL, Wisoff JH, Zeltzer PM, Boyett JM, Rorke LB, Stanley P. Effects of medulloblastoma resections on outcome in children: a report from the Children's Cancer Group. Neurosurgery 1996;38(2):265-71.

5. Wisoff JH, Boyett JM, Berger MS, et al. Current neurosurgical management and the impact of the extent of resection in the treatment of malignant gliomas of childhood: a report of the Children's Cancer Group trial no. CCG-945. J Neurosurg. 1998; 89(1): 52-9.

6. Rodriguez D, Cheung MC, Housri N, Quinones-Hinojosa A, Camphausen K, Koniaris LG. Outcomes of malignant CNS ependymomas: an examination of 2408 cases through the Surveillance, Epidemiology, and End Results (SEER) database (1973-2005).

J Surg Res. 2009;156(2):340-51.

7. Levy R, Cox RG, Hader WJ, Myles T, Sutherland GR, Hamilton MG. Application of intraoperative high-field magnetic resonance imaging in pediatric neurosurgery. J Neurosurg Pediatr. 2009;4(5):467-74.
8. Nimsky C, Ganslandt O, Von Keller B, Romstöck J, Fahlbusch R. Intraoperative high-field-strength MR imaging: implementation and experience in 200 patients. Radiology 2004;233(1):67-78.

9. Claus EB, Horlacher A, Hsu L, et al. Survival rates in patients with low-grade glioma after intraoperative magnetic resonance image guidance. Cancer 2005;103(6):1227-33.

10. Knauth M, Wirtz CR, Tronnier VM, Aras N, Kunze S, Sartor K. Intraoperative MR imaging increases the extent of tumor resection in patients with high-grade gliomas. AJNR Am J Neuroradiol. 1999;20(9):1642-6.

11. Hall WA, Martin AJ, Liu H, et al. High-field strength interventional magnetic resonance imaging for pediatric neurosurgery. Pediatr Neurosurg. 1998;29(5):253-9.

12. Hall WA, Liu H, Martin AJ, Pozza CH, Maxwell RE, Truwit CL. Safety, efficacy, and functionality of high-field strength interventional magnetic resonance imaging for neurosurgery. Neurosurgery 2000; 46(3): 632-41; discussion 641-2.

13. Alexander E 3rd, Moriarty TM, Kikinis R, Black P, Jolesz FM. The present and future role of intraoperative MRI in neurosurgical procedures. Stereotact Funct Neurosurg. 1997;68(1-4 Pt 1):10-7.

14. Moriarty TM, Kikinis R, Jolesz FA, Black PM, Alexander E 3rd. Magnetic resonance imaging therapy. Intraoperative MR imaging. Neurosurg Clin N Am. 1996;7(2):323-31.

15. Black PM, Alexander E 3rd, Martin C, et al. Craniotomy for tumor treatment in an intraoperative magnetic resonance imaging unit. Neurosurgery 1999; 45(3):423-31; discussion 431-3.

16. Marupudi NI, Altinok D, Goncalves L, Ham SD, Sood S, Apparent diffusion coefficient mapping in medulloblastoma predicts noninfiltrative surgical planes. Childs Nerv Syst. 2016;32(11):2183-87.

17. Yang JY, Beare R, Seal ML, Harvey AS, Anderson VA, Maixner WJ. A systematic evaluation of intraoperative white matter tract shift in pediatric epilepsy surgery using high-field MRI and probabilistic high angular resolution diffusion imaging tractography. J Neurosurg Pediatr. 2017;19(5): 592-605.

18. Li J, Chen X, Zhang J, et al. Intraoperative diffusion tensor imaging predicts the recovery of motor dysfunction after insular lesions. Neural Regen Res. 2013;8(15): 1400-9.

19. De la Garza-Ramos R, Kerezoudis P, Tamargo RJ, Brem H, Huang J, Bydon M. Surgical complications following malignant brain tumor surgery: an analysis of 2002-2011 data. Clin Neurol Neurosurg. 2016;140: 6-10.

20. Khomand P, Moradi G, Nooranipoor V. Incidence of cerebrovascular accidents following brain tumor surgery. ICNSJ 2017; 4(1): 29-32.

21. Gempt J, Krieg SM, Hüttinger S, et al. Postoperative ischemic changes after glioma resection identified by diffusion-weighted magnetic resonance imaging and their association with intraoperative motor evoked potentials. J Neurosurg. 2013;119(4): 829-36. 